\title{
Indicadores socioambientais: evolução e perspectivas
}

JOSÉ ELI DA VEIGA*

Social-environmental indicators: evolution and perspectives. This article deals with the balance of sustainability indicators and/or sustainable development indicators. Major gaps and blocks - both conceptual and operational - still hinder the socio-environmental governance from avoiding "blind flights".

Keywords: socio-environmental indicators; environmental governance; sustainability.

JEL Classification: Q01.

\section{INTRODUÇÃO}

Apesar de ser unânime o reconhecimento do papel crucial que poderão vir a desempenhar os indicadores socioambientais, não tem havido sequer aquele mínimo de convergência que seria necessário para que houvesse legitimação de algum (ou alguns) deles. Infelizmente, doze anos depois da adoção dos "Princípios de Bellagio" (IISD, 2000), é impossível vislumbrar alguma forma de mensurar o desenvolvimento sustentável, ou tão somente a sustentabilidade ambiental, que tenha ampla aceitação, além de respeitar seus dez critérios.

É possível que se tenha pecado por excesso de pretensão ao se estabelecer esses dez princípios. Todavia, mesmo que a referência seja apenas o quinto critério "foco prático: as avaliações devem se basear num conjunto explícito de categorias que liguem perspectivas e metas a indicadores" - é forçoso constatar que continuam a existir sérias clivagens e bloqueios, tanto conceituais quanto operacionais, para que ele seja cumprido.

Mesmo que tenham surgido muitas iniciativas de avaliação voltadas para a

\footnotetext{
* Professor titular do Departamento de Economia da FEA-USP, Universidade de São Paulo. E-mail: zeeli@usp.br. Submetido: Junho 2007; Aprovado: Maio 2008.
} 
dimensão ambiental (ou que a incluem), elas parecem ter aumentado a confusão, a ponto de existir uma espécie de nevoeiro intelectual sobre a mensuração da sustentabilidade (ambiental, ou do desenvolvimento). Por isso, a intenção básica deste trabalho é a de tentar enxergar no meio desse nevoeiro, mesmo que ainda não seja possível atravessá-lo. Para tanto, depois de fazer uma revisão dos principais indicadores disponíveis, volta-se para uma comparação empírica daqueles que parecem os mais relevantes.

\section{CRITÉRIOS PARA UMA TAXONOMIA}

Há duas características que imediatamente geram quatro categorias de indicadores de sustentabilidade: a agregação e a precificação. Por um lado, são bem distintas abordagens que se contentam com "sistemas de indicadores" ("dashboards”, CGSDI, 2002), e aquelas que se propõem a agregá-los em algum tipo de índice sintético. Por outro, também há uma verdadeira muralha entre os indicadores que assumem o desafio (ou rejeitam a necessidade) de se atribuir valores monetários aos bens e serviços ambientais. Além disso, outras diferenciações decorrentes de escolhas de dimensões, variáveis, e métodos de agregação, multiplicam o número de categorias possíveis. Mas parece óbvio que seria errado inverter esta ordem hierárquica, e enveredar por uma prévia classificação dos indicadores por tais escolhas, para só depois considerar se eles são ou não monetários e/ou sintéticos. As revisões que não estabelecem esses dois "divisores de águas" acabam contribuindo para que o "nevoeiro" fique ainda mais espesso. Ver, por exemplo, OECD $(2001,2003)$.

Por mais importante que seja a construção de "sistemas de indicadores" ("dashboards"), isoladamente eles terão pequena influência na governança socioambiental, porque ferem pelo menos três dos princípios de Bellagio, além do quinto (já citado): a) não garantem comunicação eficiente; b) dificultam ampla participação; c) dificilmente podem orientar visão e metas.

Assim, essa opção por sistemas/ "dashboards", como são os "Indicadores de Desenvolvimento Sustentável” do IBGE (2002, 2004), ou o "GeoBrasil”, do PNUMA /MMA/Ibama (2002), deve ser muito valorizada, mas sobretudo como matéria-prima (base de dados) para a elaboração de indicadores com algum nível de agregação ou de síntese.

Já a segunda separação - unidades monetárias ou físicas - não é tão simples de ser superada, pois decorre, em última instância, de concepções teóricas muito distintas da sustentabilidade (ambiental ou do desenvolvimento). Essas duas abordagens têm tido evoluções paralelas, com apoios institucionais bem distintos, sem que seja possível prever no momento algum tipo de "vitória" de uma delas em termos de legitimação, constatação inescapável também feita em outra abordagem por Costa e Lustosa (2007). 


\section{A ABORDAGEM MONETÁRIA}

Avaliações negativas da abordagem monetária podem ser encontradas em dois importantes trabalhos recentemente publicados no Brasil: Hales e Prescott-Allen (2005) e Gadrey e Jany-Catrice (2006). No primeiro há um curto e liminar descarte das tentativas de esverdear o PIB, assim como de dois outros indicadores considerados dignos de destaque: o Índice de Bem-Estar Econômico Sustentável (IBES, "ISEW") e o Indicador de Progresso Genuíno (IPG, "GPI").

A primeira versão do IBES ("ISEW") surgiu em 1989 nos Estados Unidos, como um anexo do famoso livro "For the Common Good", de John Cobb e Herman Daly. Depois houve uma enxurrada de iniciativas similares: Canadá, Alemanha, Reino Unido, Áustria, Países Baixos e Suécia. Uma boa revisão dessas iniciativas está em trabalho de Jackson \& Stymne (1996), publicado pelo Instituto do Meio Ambiente de Estocolmo. E uma discussão contraditória e muito técnica foi feita por Cobb e Cobb (1994) e por Cobb, Halstead e Rowe (1995).

O IPG ("GPI"), indicador hoje razoavelmente conhecido nos Estados Unidos, e bastante parecido em inspiração e método com o IBES ("ISEW"), foi concebido pelos pesquisadores da ONG "Redefining Progress", criada em 1994. Depois que começou a ser divulgado, a partir de 1995, também foi sendo adaptado por institutos de pesquisa de outros países: Alemanha, Reino Unido, Canadá e Austrália.

As dificuldades de imputação de valores monetários a bens e serviços ambientais são apontadas como o "calcanhar de aquiles dessas e outras abordagens similares" (Hales \& Prescott-Allen, 2005, p. 50). Todavia, em ralação ao segundo, a crítica é bem mais moderada. E a detalhada apresentação desses dois índices decorrentes das discussões sobre "PIB verde", feita por Gadrey e Jany-Catrice (2006, pp. 96 e 100) e traz três gráficos que ilustram bem os declínios do "bem-estar sustentável por habitante" entre 1974 e 1990, no Reino Unido, na Suécia (IBES, "ISEW") e nos Estados Unidos (IPG, “GPI").

Entretanto, o indicador monetário que parece ganhar mais proeminência nos últimos anos rompeu radicalmente com essa ideia inicial de corrigir o PIB. Principalmente ao assumir que o crescimento econômico deve ser visto como crescimento de riqueza per capita, e não de crescimento de produto per capita, já que o PIB não inclui a depreciação de muitos ativos, como a degradação de ecossistemas. Assim, o PIB per capita pode crescer ao mesmo tempo em que a riqueza per capita diminui. "O PIB pode ser um índice inapelavelmente enganoso de bem-estar humano", diz Dasgupta (2005, p. 98).

Nessa linha de raciocínio, que tem sido estimulada pelo Banco Mundial, procura-se calcular uma "poupança genuína” ("genuine savings”), logo rebatizada de "poupança líquida ajustada" ("adjusted net savings"). Começa-se por subtrair o consumo de capital fixo da poupança interna bruta. Em seguida são adicionados os investimentos em educação. E finalmente são subtraídas as principais manifestações da míngua do capital natural (redução dos recursos energéticos, minerais e florestais, e danos causados pelas emissões de dióxido de carbono) (World Bank, 2005).

O problema é que existe uma grande disparidade nos cálculos do Banco Mun- 
dial entre os bens ambientais aos quais é fácil atribuir valores monetários e aqueles para os quais isso se mostra muito difícil, para não dizer impossível. Parecem bem consistentes os dados referentes à depreciação de recursos como petróleo, gás natural, minerais, a extração de madeira das florestas, ou o uso da atmosfera para despejar gás carbônico.

Entre os muitos tipos de capital natural cuja depreciação não aparece nas estatísticas publicadas no relatório Where is the Wealth of Nations? (2005) estão: água potável, solo, áreas de pesca oceânicas, florestas e manguezais como provedores de serviços ecossistêmicos, assim como a atmosfera como destino de particulados, nitrogênio e óxidos de enxofre. Além disso, os preços estimados pelo Banco Mundial baseiam-se em premissas que ignoram a capacidade limitada dos sistemas naturais recuperarem-se de perturbações (a resiliência).

Todavia, o principal motivo de estranheza com essa nova abordagem monetária não é de ordem técnica. Mesmo que se possa prever um forte aumento de seu poder persuasivo, caso venham a ser superadas essas óbvias limitações empíricas, a grande questão de fundo é que essa metodologia se baseia na ideia de que existe a possibilidade de completa substituição entre os três fatores: trabalho, capital e recursos naturais. Isto é, entre capital humano, capital construído e capital natural, na linguagem que preferem.

Há muito tempo esta questão vem sendo enfatizada pelos pioneiros da "Economia Ecológica", e também pelos adeptos menos fundamentalistas da "Economia Ambiental". Trata-se, enfim, de uma concepção que só é aceita por seguidores ortodoxos da teoria neoclássica do bem-estar, e de sua decorrente "sustentabilidade fraca". Exposições sistemáticas sobre essa clivagem podem ser encontradas em Amazonas (2002), Romeiro (2003), Mueller (2004) e Veiga (2005, 2006).

\section{A ABORDAGEM FÍSICA}

Segundo Hales e Prescott-Allen (2005) haveria pelo menos meia dúzia de índices que, com diferentes graus e formas de agregação, visam fazer uma avaliação sintética da sustentabilidade (ambiental, ou do desenvolvimento). A rigor, seriam mais de seis, pois os autores simplesmente ignoram, por exemplo, o "Environmental Degradation Index", construído pelos professores Raghbendra Jha e K.V. Bhanu Murthy, respectivamente da Universidade Nacional da Austrália e da Universidade de Delhi (Jha \& Murthy, 2003a, 2003b). E também não consideram os esforços que estão sendo feitos na direção de estabelecer "perfis metabólicos" dos países, que seria o melhor caminho segundo o ex-presidente da Sociedade Internacional de Economia Ecológica, Joan Martinez-Alier (2005). O problema é que indicadores elaborados por alguns indivíduos - sejam eles professores universitários, pesquisadores ou consultores - não podem ser equiparados àqueles que já foram assumidos por organizações internacionais de grande prestígio em assuntos ambientais. Por exemplo, o "barômetro de sustentabilidade", montado por Robert Prescott-Allen (2001), teria outra importância se, de fato, tivesse sido assumido pela IUCN. No 
entanto, ao contrário do que sugere em Hales e Prescott-Allen (2005), não se encontra esse índice no "site" da União Conservacionista Mundial (www.iucn.org). O mesmo pode ser dito sobre dois outros - "compasso de sustentabilidade" e "painel de sustentabilidade", que Tony Atkinson, da Universidade de Oxford, teria elaborado para o Instituto Internacional de Desenvolvimento Sustentável (IISD). Neste caso, nem sequer é possível acessar sua página web (www.iisd.org).

Na prática, os únicos índices de sustentabilidade que adquiriram grande visibilidade internacional são os divulgados pelo WWF ("World Wide Fund for Nature", anteriormente "World Wildlife Fund"), e pelo WEF ("World Economic Fórum"), estes calculados por duas das mais importantes instituições acadêmicas da área: o Yale Center for Environmental Law and Policy, e o Center for International Earth Science Information Network, da Universidade de Columbia.

Como um dos índices do WWF - o Índice Planeta Vivo ("Living Planet Index") - não chega a ser um indicador de sustentabilidade, pode-se dizer, então, que, ao fim e ao cabo, existem hoje quatro índices de sustentabilidade ambiental com ampla visibilidade global: dois do WWF e dois do WEF. Desde 1998, os relatórios bienais do WWF comparam a "Pegada Ecológica" de cada país, tanto com a biocapacidade média do planeta, quanto com sua biocapacidade específica, dois indicadores de balanço ecológico (tudo em hectares globais). E, desde 2002, os estudos apoiados pelo WEF fornecem dois índices sintéticos: o Índide de Sustentabilidade Ambiental, ISA ("ESI" - "Environmental Sustainability Index"), e o Índice de Desempenho Ambiental, IDA ("EPI" - "Environmental Performance Index").

O Índice Planeta Vivo é um indicador sintético da biodiversidade global, que se baseia no estado de mais de 3.600 populações de 1.313 espécies de vertebrados. Composto de três dimensões que acompanham 695 espécies terrestres, 274 marítimas e 344 de água doce. O "Living Planet Report 2006" mostrou essencialmente que o declínio da biodiversidade global no período 1970-2003 foi de assustadores 30\%. Descrição detalhada desses cálculos está em Loh et al. (2005). Ver também: http://www.panda.org/.

A famosa Pegada Ecológica ("Ecological Footprint”) mede a pressão que a humanidade está exercendo sobre a biosfera, representada pela área biologicamente produtiva (tanto terrestre quanto marítima) que seria necessária para a provisão dos recursos naturais utilizados e para a assimilação dos rejeitos. (O consumo de água doce é tratado em separado por ser impossível expressá-lo em hectares globais.) Uma vez obtida essa "pegada", para qualquer unidade territorial (localidade, região, país etc.), ela pode ser comparada à "capacidade biológica" (tanto média do planeta quanto específica), também apresentada em hectares globais. $\mathrm{O}$ mais recente resultado dessa comparação é que, em 2003, a pressão exercida pela humanidade foi $25 \%$ superior à capacidade da biosfera de atendê-la com serviços ecossistêmicos e absorção de seu lixo (Wackernagel et al., 2005). O "Ecological Footprint" agora conta com rede global que disponibiliza informações bem detalhadas sobre metodologia, fontes de dados, hipóteses e definições: http://www. footprintnetwork.org/.

O Índice de Sustentabilidade Ambiental ("Environmental Sustainability Index”) 
envolve cinco dimensões: sistemas ambientais, estresses, vulnerabilidade humana, capacidade social e institucional, e responsabilidade global. O primeiro considera quatro sistemas ambientais: ar, água, solo e ecossistemas. O segundo considera estresse algum tipo muito crítico de poluição, ou qualquer nível exorbitante de exploração de recurso natural. No terceiro, a situação nutricional e as doenças relacionadas ao ambiente são entendidas como vulnerabilidades humanas. A quarta dimensão se refere à existência de capacidade socioinstitucional para lidar com os problemas e desafios ambientais. E na quinta entram os esforços e esquemas de cooperação internacional representativos da responsabilidade global.

O Índice de Desempenho Ambiental ("Environmental Performance Index") resultou das críticas que foram dirigidas à dimensão ambiental das Metas do Milênio, das Nações Unidas. Ele está centrado em dois amplos objetivos de proteção: (a) reduzir os estresses ambientais na saúde humana, e (b) promover vitalidade ecossistêmica e consistente gestão dos recursos naturais. Utiliza dezesseis variáveis relacionadas a seis tipos de políticas bem estabelecidas: Saúde Ambiental, Qualidade do Ar, Recursos Hídricos, Recursos Naturais Produtivos, Biodiversidade e Habitat, e Energia.

O sétimo objetivo das Metas do Milênio - "Garantir a sustentabilidade ambiental" - tem as seguintes metas: "Integrar os princípios do desenvolvimento sustentável nas políticas e programas nacionais e reverter a perda de recursos ambientais até 2015"; "Reduzir à metade, até 2015, a proporção da população sem acesso sustentável à água potável segura"; "Até 2020, ter alcançado uma melhora significativa nas vidas de pelo menos 100 milhões de habitantes de bairros degradados". Para isso dispõe de oito indicadores. Duas outras são essencialmente metas sociais, pois se preocupam com o acesso das populações ao saneamento, à água potável, e à habitação. Discute-se a necessidade de incluir uma meta específica para biodiversidade nesse objetivo. Os cinco indicadores da nona meta são os que mais se assemelham a uma avaliação de sustentabilidade ambiental: "Proporção da área de terras cobertas por vegetação natural”; "Área de terras protegidas para manter a diversidade biológica sobre a superfície total"; "Uso de energia por U\$ 1,00 do PIB"; "Emissões per capita de $\mathrm{CO}_{2}$ e consumo de CFC eliminadores de ozônio"; e finalmente "Proporção da população que utiliza combustíveis sólidos" (Cechin \& Setzer, 2006).

Além de duas páginas de comentários sobre outros esforços de medir a sustentabilidade ambiental, o Relatório do ESI-2005 ("2005 Environmental Sustainability Index Report”) traz também um apêndice específico com discussão técnica comparativa. No que se refere à Pegada Ecológica, há um reconhecimento de seu apelo intuitivo, já que a depleção dos recursos naturais é um elemento central da sustentabilidade. No entanto, esse é considerado apenas um dos aspectos que precisam entrar num índice sintético de sustentabilidade ambiental, como pretende ser o ISA ("ESI"). E a relação entre os dois índices patrocinados pelo WEF é explicada em outro apêndice, desta vez do relatório do EPI-2006 ("Pilot 2006 Environmental Performance Index"). Segundo seus criadores, o ISA ("ESI”) deve ser entendido como algo mais estrutural, ao lado do IDA (“EPI”), bem mais focado no esforço 
que o país está fazendo para melhorar seu desempenho ambiental. Informações detalhadas sobre todas essas diferenças podem ser encontradas em: http://sedac. ciesin.columbia.edu/es/esi/.

Comparando os números desses dois pares de índices, fica imediatamente claro que os do WEF tendem a ser bem mais favoráveis a uma boa avaliação dos países mais ricos e mais desenvolvidos, enquanto ocorre exatamente o oposto com os do WWF. E o contraste não poderia ser mais forte. Considerando-se, por exemplo, a lista dos 57 países que em 2003 tinham IDH superior a 0,800 (classificados como de "alto desenvolvimento" pelo PNUD), houve apenas nove reprovações pelo ISA ("ESI"), e apenas uma pelo IDA ("EPI"). Ou seja, 48 países desenvolvidos teriam razoável sustentabilidade e bom desempenho ambiental. Os mal avaliados pelo ISA ("ESI") foram: Bélgica, Espanha, Coreia do Sul, República Tcheca, Polônia, Emirados Árabes Unidos, Kuwait, México e Trinidad e Tobago. E pelo IDA ("EPI") somente um: o México.

No extremo oposto, dessa mesma lista apenas dez mostravam ter reserva (balanço ecológico positivo, quando se subtrai a pegada ecológica da biocapacidade nacional), segundo os critérios do WWF. E apenas um tinha pegada ecológica inferior à média global. Ou seja, 46 países desenvolvidos estariam mostrando, ao contrário, não ter sustentabilidade ambiental. Tinham biocapacidade superior às suas pegadas ecológicas os seguintes países: Noruega, Austrália, Canadá, Suécia, Finlândia, Nova Zelândia, Argentina, Chile, Uruguai, Letônia e Panamá. E apenas Cuba tinha pegada inferior à biocapacidade média global de 1,8 hectare global.

Também existe contraste de avaliação para os demais 120 países para os quais o IDH foi calculado em 2003. Pelo ISA ("ESI"), 37 deles teriam razoável sustentabilidade ambiental, e, pelo IDA ("EPI"), 26 teriam bom desempenho ambiental. Já os cálculos do WWF sugerem que 78 desses países tinham pegadas ecológicas inferiores à biocapacidade média global (1,8 ha), e 46 tinham reservas, isto é, balanços ecológicos positivos quando a pegada era subtraída de sua própria biocapacidade.

Dados igualmente interessantes sobre esse tipo de comparação entre o IDH e o ISA ("ESI"), embora bem menos incisivos, resultaram de trabalho que embutiu o segundo como se fosse uma quarta dimensão do primeiro, obtendo assim o que foi batizado de "IDH-Híbrido (IDHh)". Nesse caso, os Estados Unidos, por exemplo, caem da oitava posição no ranking do IDH para a décima quinta no do IDHh (Martins et al., 2006).

É claro que as diferenças de metodologia entre esses dois pares de índices têm consequências que vão muito além de meras discrepâncias de avaliação empírica. Para que resultados referentes aos países desenvolvidos sejam tão contrastantes, e para que haja tanta diferença entre as avaliações dos demais, tem de haver diferença de fundo. Diferença de ordem conceitual sobre os sentidos que esses dois grupos de especialistas que prepararam os indicadores do WWF e do WEF atribuem às noções de sustentabilidade ambiental, desempenho ambiental e desenvolvimento sustentável. 


\section{O CONTRASTE ENTRE AS VISÕES DO WWF E DO WEF}

Enquanto os dois índices do WWF são essencialmente "objetivos", pois monitoram a situação de vertebrados como indicadora da biodiversidade, e comparam pressões antrópicas ("pegadas") a biocapacidades, os dois índices do WEF tendem a diluir esse tipo de avaliação ao agregarem dimensões de caráter "subjetivo". Por exemplo, a "capacidade socioinstitucional", na qual há quatro variáveis para captar a "capacidade de debate", oito para a "governança ambiental", e cinco para a "capacidade de resposta do setor privado".

Uma maneira de ilustrar a influência que exercem as dimensões e variáveis subjetivas é observar os desempenhos do grupo formado pelos 26 países mais desenvolvidos, para os quais estão disponíveis, tanto as avaliações das cinco dimensões do ESI, quanto suas respectivas pegadas e biocapacidades. Por países mais desenvolvidos entende-se não apenas os que têm altos IDH (superior a 0,800), mas que também têm altos desempenhos em suas três dimensões: longevidade, educação e renda per capita (Sachs, 1991; Ryten, 2000).

Pelos critérios “objetivos" do WWF, todos esses 26 países mais desenvolvidos estão exercendo uma pressão sobre a capacidade biológica bem mais alta do que a média global de 1,8 hectare. Suas pegadas variam de 3,2 a 9,6 hectares globais. E quando é feito o balanço entre essas pegadas e suas respectivas biocapacidades, apenas meia dúzia não são deficitários: Nova Zelândia $(9,0)$, Canadá $(6,9)$, Austrália $(5,9)$, Finlândia $(4,4)$, Suécia $(3,5)$ e Noruega $(0,9)$.

Por uma das dimensões mais "objetivas" do ESI, focada na "redução de estresses ambientais", praticamente todos os países mais desenvolvidos foram reprovados. Uma única exceção: a Finlândia. Na outra dimensão que também pode ser considerada "objetiva", a dos próprios "sistemas ambientais", mais da metade (15) foi mal avaliada. Por ordem decrescente, os mais estressados são: Bélgica, Holanda, Coreia do Sul, Espanha, Israel, Japão, República Tcheca, Itália, Grécia, Reino Unido, Alemanha, Dinamarca, Portugal, França e Eslováquia.

Nenhum deles se saiu mal da terceira dimensão, relativa à "vulnerabilidade humana". O mesmo aconteceu com a quarta dimensão, intitulada "Capacidade social e institucional". E pelo critério da cooperação internacional ("Global Stewardship”), houve 11 reprovados: Canadá, República Tcheca, Austrália, Eslováquia, Espanha, Nova Zelândia, Estados Unidos, Grécia, Eslovênia, Reino Unido e Itália. Assim, no índice agregado (ESI), apenas quatro dos 26 (15\%) obtiveram nota baixa: Coreia do Sul, Bélgica, República Tcheca e Espanha.

É aqui que começa a surgir a grande diferença conceitual entre o balanço ecológico proposto pela abordagem da pegada (WWF) e o principal índice construído pelos grupos de pesquisa de Yale e Columbia (WEF). Para o WWF, “o progresso com vista ao desenvolvimento sustentável" pode ser avaliado através do IDH como indicador de bem-estar, e da Pegada Ecológica como uma medida da exigência humana na biosfera. Todavia, não é o saldo entre a pegada e a biocapacidade de cada país que o WWF coteja com o IDH, e sim a "biocapacidade média disponível por pessoa no planeta, que poderia denotar sustentabilidade ao nível 
global” (WWF, 2006, p. 19). Assim, o único país que está atendendo aos dois critérios - IDH superior a 0,800 e Pegada Ecológica inferior a 1,8 hectare global - é Cuba.

Seria possível admitir, entretanto, que Cuba seja um país desenvolvido? Atingiu um IDH de 0,817 porque teve ótimo desempenho na educação $(0,91)$, e bom na saúde $(0,87)$. Mas continua a ser um país muito pobre, com uma renda per capita que não chega a $70 \%$ da brasileira. É evidentemente por isto que é tão baixa sua exigência, quando avaliada pela Pegada Ecológica (1,5 ha). Trata-se, portanto, de uma avaliação surpreendente, já que, mesmo com tão baixa pegada, seu balanço ecológico é negativo. Como sua biocapacidade é de apenas 0,9 , deixa um déficit de - 0,7. A rigor, um país como o Equador, por exemplo, deveria ter avaliação superior à de Cuba, pois tem pegada idêntica, mas biocapacidade superior $(2,2)$, o que gera uma reserva de 0,7 hectares globais. E seu IDH só não ultrapassa os 0,800 porque a renda per capita é ainda menor do que a cubana $(47 \%$ da brasileira), já que também são altos seus resultados em educação e saúde: 0,86 e 0,82, respectivamente.

Caso simétrico é o da Finlândia, o único dos 26 países mais desenvolvidos bem avaliado em todas as dimensões do ESI, inclusive na segunda, a mais objetiva e exigente, que se refere à redução dos estresses ambientais, na qual todos os demais foram reprovados. Por esse prisma, a Finlândia é o país do núcleo dos mais desenvolvidos que demonstra a mais robusta sustentabilidade ambiental. No entanto, sua Pegada Ecológica é a segunda maior do planeta $(7,6)$, só superada pela dos Estados Unidos, e empatada com a do Canadá. Por outro lado, sua biocapacidade também é alta $(12,0)$, o que a coloca entre os parcos seis países desse grupo que têm alguma reserva.

Enfim, é muito difícil lidar com a ideia de que os melhores exemplos de países que estariam na trilha do desenvolvimento sustentável poderiam ser Cuba (pela visão do último "Living Planet Report", do WWF), ou a Finlândia (pelo resultado do último relatório do ESI, patrocinado pelo WEF). E são esses tipos de dúvidas que corroem a possibilidade de que algum desses índices venha a ter aceitação e legitimidade comparáveis às que o IDH conseguiu obter como índice de desenvolvimento.

\section{O “ESTADO DA ARTE” NO BRASIL}

Tudo indica que a reflexão mais amadurecida já feita no Brasil sobre indicadores para a governança ambiental esteja em recente dissertação de mestrado (junho de 2006) em estudos populacionais e pesquisas sociais (área de concentração: estatística social), orientada na ENCE - Escola Nacional de Ciências Estatísticas pelo professor Paulo de Martino Jannuzzi. É uma proposta para construção e representação de indicadores de desenvolvimento sustentável (e sua aplicação para os municípios fluminenses) que procura superar a relação dicotômica entre "sistemas de indicadores" ("dashboards") e "indicadores sintéticos" (ou "agregados"). 
Daí seu autor - Wadih João Scandar Neto - ter escolhido por título uma frase que aparentemente nada tem a ver com o tema: "Síntese que organiza o olhar".

$\mathrm{Na}$ verdade, o que ele propõe é um inédito modo de combinar e apresentar simultaneamente o índice sintético e os indicadores por dimensão, por temas e por variável. Ou seja, enfrentou o desafio de chegar a um indicador de desenvolvimento sustentável, mas de modo a manter sua vinculação com os níveis menos agregados, ou inteiramente desagregados. E sua aplicação permite que numa consulta se possa enxergar para cada município fluminense, tanto seu índice sintético de desenvolvimento sustentável, quanto os indicadores das quatro dimensões (ambiental, econômica, institucional e social), dos onze temas (atmosfera, terra, saneamento; capacidade econômica e padrões de produção e consumo; capacidade institucional; rendimento, saúde, educação, habitação e violência), e mesmo das trinta variáveis.

Todavia, ao lado dessa extraordinária contribuição metodológica - bem mais sofisticada que qualquer outra solução conhecida para o problema da referida dicotomia entre "sistemas de indicadores" e "índices sintéticos" - há uma debilidade de conteúdo. Ela decorre da "decisão pragmática" de adotar o rol de indicadores disponibilizados pela publicação Indicadores de Desenvolvimento Sustentável Brasil, 2004, do IBGE (Scandar Neto, 2006, p. 47; Bolliger \& Scandar Neto, 2004). Problema que, no fundo, decorre da insuficiência do sistema estatístico nacional em suprir informações para a escala municipal sobre a totalidade dos temas envolvidos. Fosse qual fosse a opção, as variáveis para construção de qualquer índice de desenvolvimento sustentável municipal seriam poucas para as dimensões ambiental e institucional.

A dimensão ambiental compreende três variáveis relativas ao tema "Saneamento", duas relativas ao tema "Atmosfera", e apenas uma relativa ao tema "Terra". As do "Saneamento" são três "proporções de moradores com acesso a": (i) sistema de abastecimento de água; (ii) coleta de lixo doméstico; (iii) esgotamento sanitário. As do tema "Atmosfera" são: (iv) Frota de veículos automotores por cem habitantes; (v) potencial de poluição industrial por mil habitantes. E a única do tema "Terra" é: (vi) percentual de área de vegetação remanescente sobre área total.

O mais estranho ocorre na avaliação da "Capacidade Institucional”, único tema da dimensão "Institucional”. Suas duas variáveis são: (i) proporção de municípios com possibilidade de acesso à internet; e (ii) número de terminais telefônicos instalados por cem habitantes. Talvez fosse até razoável para avaliar as telecomunicações, mas não faz qualquer sentido para avaliar "capacidade institucional".

Como não poderia deixar de ser, foram mais bem escolhidas as variáveis para as dimensões "Social" e "Econômica", o que evidentemente reflete a diferença de tradição estatística entre esses dois campos e os novíssimos "ambiental" e "institucional”, como evidencia a coletânea organizada por Romeiro (2004). O que permite concluir que o Índice construído por Scandar Neto (2006) para seu exercício empírico até está bem razoável para medir o "desenvolvimento", mas é frágil demais para medir a "sustentabilidade". Nesse sentido, resistiria bem em alguma comparação com o IDH e correlatos, mas sua dimensão ambiental não poderia ser comparada ao ESI ou à Pegada Ecológica. 
Há outra dissertação de mestrado que certamente trouxe contribuição importante para essa necessidade de indicadores que venham a contribuir para a governança ambiental no Brasil. Foi concluída em 2001, no programa de pós-graduação em planejamento urbano e regional (Propur) da UFRGS, orientada pelo professor Carlos André Bulhões Mendes. Mas seu autor - Ricardo Luiz Dobrovolski - preferiu usar outra expressão: "perfis" de desenvolvimento sustentável, em vez de "indicadores" ou "índices". Procurou fazer tanto uma "quantificação", quanto uma "análise espacial” para o caso gaúcho.

Para determinar os perfis ambientais locais, foi adotada a média aritmética de três indicadores: taxa de áreas naturais; poluição hídrica industrial; poluição atmosférica. A fonte do primeiro (áreas naturais) foi o inventário florestal realizado pela Universidade Federal de Santa Maria para a Secretaria Estadual de Meio Ambiente. Para o segundo (poluição hídrica) foram adotadas duas variáveis derivadas de publicações da Fundação Estadual do Meio Ambiente (Fepam): toxidade dos efluentes e respectivas cargas orgânicas. E o terceiro (poluição atmosférica) foi definido por duas variáveis relativas às emissões: industriais e veiculares. Para as industriais foi usado um diagnóstico feito pela Fepam em 1997, e para as veiculares houve uma estimativa baseada no número de veículos por município, e em fatores de emissão por tipo de veículo (estabelecidos em 1999 pela Cetesb).

Outra vez, parece ter sido bem mais simples o estabelecimento dos perfis sociais e econômicos, pois o estado do Rio Grande do Sul dispõe de larga tradição e excelência, como mostra a produção de sua Fundação de Economia e Estatística Siegfried Emanuel Heuser (FEE). Então, para definir os perfis municipais de desenvolvimento sustentável, foi utilizada não apenas a média aritmética dos três perfis (ambiental, social e econômico), mas também um método de ponderação espacial baseado em técnica de regressão geograficamente ponderada. Dessa forma, foram elaborados dois perfis para cada município. Um considera exclusivamente os aspectos locais, e outro também contabiliza as condições do entorno. Assim, além de disponibilizar duas informações, a abordagem também permite uma avaliação das relações espaciais (Dobrovolski, 2004, p. 237).

Finalmente - mas longe de ser menos importante - é fundamental que sejam destacadas aqui outras três contribuições: pesquisa do Departamento de Engenharia Ambiental da Escola Politécnica da UFBa (Agra Filho et al., 2005; SEI, 2006), tese de doutorado de Estela Neves defendida em 2006 na UFRRJ (CPDA), sob a orientação do professor Peter Herman May, e cálculo do PIB verde industrial dos estados do Nordeste como indicador de sustentabilidade (Ferreira Jr. \& Lustosa, 2007).

No primeiro caso, a análise dos modelos disponíveis de sistematização de indicadores de sustentabilidade ambiental levou à preferência por uma abordagem mais desagregada representada por um modelo que foi denominado de "FPEIR": "Força Motriz $\rightarrow$ Pressão $\rightarrow$ Estado $\rightarrow$ Impacto $\rightarrow$ Resposta". No entanto, a adoção de tal modelo parece esbarrar em "circunstâncias da logística disponível na sistematização das informações requeridas" (Agra Filho et al., 2005, p. 743). No segundo, a tese de Neves (2006) é, sem dúvida, o trabalho mais sistemático que já foi feito sobre o assunto, embora não seja focada especificamente em indicado- 
res para a governança socioambiental, e sim na disponibilidade de recursos municipais para políticas de defesa do meio ambiente. E com a vantagem de ter optado por uma abordagem institucional, cuja influência será muito saudável. E o terceiro serve como exemplo do quanto podem ser discutíveis tentativas de mero ajuste do PIB para a obtenção de um indicador de sustentabilidade.

\section{CONCLUSÕES}

A principal conclusão foi antecipada na introdução: é impossível vislumbrar alguma forma de mensurar o desenvolvimento sustentável, ou tão somente a sustentabilidade ambiental, que possa vir a ter ampla aceitação. Todavia, vêm surgindo muitas iniciativas que procuram se aproximar de tão ambicioso propósito.

Por isso, também parece possível tirar uma conclusão secundária, sobre as duas principais dificuldades, mesmo que seja dificílimo afirmar qual das duas pode ser considerada a mais séria: se a incipiência dos bancos de dados primários sobre $o$ meio ambiente, ou se a incipiência conceitual sobre o que realmente pode ser a sustentabilidade ambiental. Como foi necessário meio século para que essas duas debilidades fossem superadas no âmbito do substantivo "desenvolvimento", só se pode torcer para que não seja necessário esperar mais quatro décadas para que o mesmo ocorra no âmbito do adjetivo "sustentável". Enquanto isso, não haverá como evitar que a governança socioambiental dependa de muitos "voos cegos", para usar a feliz expressão de Hales e Prescott-Allen (2005).

Por último, mas talvez muito mais importante, é necessário colocar em dúvida a tendência dominante nos estudos revistos neste artigo a vários tipos de desqualificação das tentativas de corrigir, ou "esverdear" o cálculo do PIB, e até de propostas de revisão da própria noção de riqueza que o fundamenta. É provável que em futuro próximo vários esforços possam convergir para uma radical reformulação dos métodos de contabilidade nacional que faça emergir um indicador de progresso material que supere as inúmeras limitações do PIB. O que seria, de resto, uma das principais inovações institucionais do século XXI.

Tal prognóstico, que deriva de pesquisa em curso cujos resultados serão objeto de um próximo artigo, foi reforçado entre 2007 e 2008 por três importantes sinais. O primeiro está no sentido geral das contribuições publicadas pela revista Ecological Economics 61(4), número especial sobre a avaliação do SEEA: System of Integrated Environmental and Economic Accounting, que juntou esforços das divisões de estatísticas da ONU, da Comissão Europeia, do FMI, da OCDE, e do Banco Mundial (Lange, 2007). O segundo na realização da conferência "Beyond GDP”, promovida pela Comissão Europeia, Parlamento Europeu, OCDE, Clube de Roma e WWF, em Bruxelas, novembro de 2007 (Wesselink et al., 2007). E o terceiro no fato de Joseph Stiglitz e Amartya Sen terem aceitado o desafio feito no início de 2008 pelo presidente francês Nicolas Sarkozy para que liderem uma ampla articulação internacional de superação do PIB como indicador da "qualidade de vida”. 


\section{REFERÊNCIAS BIBLIOGRÁFICAS}

AGRA Filho, Severino SOARES, Márcia Mara de OLIVEIRA Marinho, Felipe PEREIRA, Rejane SANTANA \& Raul MENDES (2005) "Análise e proposição de um modelo de indicadores de sustentabilidade ambiental”, Bahia Análise \&o Dados, SEI, Salvador, v. 14, n. 4: 733-744.

AMAZONAS, Maurício de Carvalho (2002) "Desenvolvimento sustentável e teoria econômica: o debate conceitual nas perspectivas neoclássica, institucionalista e da economia ecológica”. In: NOBRE, Marcos \& Maurício AMAZONAS (orgs.) Desenvolvimento Sustentável. A institucionalização de um conceito. (Parte II). Brasília: Ed. Ibama, 2002.

BOLLIGER, Flavio Pinto \& Wadih João SCANDAR NETO (2004) "Estatísticas ambientais e indicadores de desenvolvimento sustentável no Brasil”, capítulo 15 de ROMEIRO, Ademar Ribeiro (org.) (2004). Avaliação e contabilização de impactos ambientais. São Paulo: Ed. Unicamp \& Imprensa Oficial: 271-297.

CECHIN, Andrei \& Joana SETZER (2006) "Biodiversidade: nova dimensão dos Objetivos de Desenvolvimento de Milênio”. Texto apresentado na III Conferência Mundial para as Relações Internacionais. Brasília, 10 de outubro, 2006.

CGSDI (2002) Consultative Group on Sustainable Development Indicators. "Dashboard of Sustainable Development Indicators”, Base de dados em 9 de janeiro de 2002.

COBB, C., T. HALSTEAD \& J. ROWE (1995) The Genuine Progress Indicator: Summary of Data and Methodology, San Francisco, CA: Redefining Progress, 1995.

COBB, C. \& J. COBB, (1994) The Green National Product: a Proposed Index of Sustainable Economic Welfare, Washington, DC: University Press of America, 1994.

COBB, John \& Herman DALY (1989) For the Common Good: Redirecting the Economy toward Community, the Environment and a Sustainable Future, Boston: Beacon Press, 1989.

COSTA, Marcio Jorge PORANGABA \& Maria Cecília Junqueira LUSTOSA (2007) "Mensuração do desenvolvimento socioeconômico e ambiental", trabalho apresentado no "VII Encontro da Sociedade Brasileira de Economia Ecológica - EcoEco". Fortaleza, 28 a 30 de novembro de 2007.

DASGUPTA, Partha (2005) "Uma abordagem dosada" (contraponto ao artigo "Sustentabilidade em um mundo lotado", de Herman E. Daly) Scientific American Brasil, outubro 2005: 98.

DOBROVOLSKI, Ricardo Luiz (2004) "Perfis de desenvolvimento sustentável: quantificação e análise espacial para o estado do Rio Grande do Sul”, capítulo 14 de ROMEIRO, Ademar Ribeiro (org.) (2004). Avaliação e contabilização de impactos ambientais. São Paulo: Ed. Unicamp \& Imprensa Oficial: 231-251.

ESI (2005) - 2005 Environmental Sustainability Index. (Global Leaders of Tomorrow Environmental Task Force - World Economic Forum). In collaboration with: Yale Center for Environmental Law and Policy, Yale University; Center for International Earth Science Information Network, Columbia University. http://www.ciesin.columbia.edu.

FERREIRA Jr., Humberto Barbosa \& Maria Cecília Junqueira LUSTOSA (2007) "PIB verde industrial dos estados no Nordeste como indicador de sustentabilidade", trabalho apresentado no "VII Encontro da Sociedade Brasileira de Economia Ecológica - EcoEco". Fortaleza, 28 a 30 de novembro de 2007.

GADREY, Jean \& Florence JANY-CATRICE (2006) Os Novos indicadores de riqueza. São Paulo: Ed. Senac, 2006.

HALES, David \& Robert PRESCOTT-ALLEN (2005) "Voo cego: avaliação do progresso rumo à sustetnabilidade”. In: ESTY Daniel C. \& Maria H. IVANOVA (orgs.) Governança Ambiental Global - Opções e Oportunidades, S.Paulo: Ed. Senac, 2005: 39-62.

IBGE (2002). Instituto Brasileiro de Geografia e Estatística. Indicadores de Desenvolvimento Sustentável, Brasil 2002. IBGE - Diretoria de Geociências. Rio de Janeiro: IBGE, 2002. (Estudos \& Pesquisas - Informação Geográfica, n. 2).

IBGE (2004) Instituto Brasileiro de Geografia e Estatística. Indicadores de Desenvolvimento Sustentável 2004 Brasil. IBGE - Diretoria de Geociências. Rio de Janeiro: IBGE, 2004. 
IISD (2000) International Institute for Sustainable Development, Bellagio Principles, Winnipeg, IISDnet, 2000, disponível em http://iisd1.iisd.ca/measure/bellagio1.htm.

JACKSON, T. \& S. STYMNE (1996) "Sustainable economic welfare in Sweden: a Pilot Index 1950-1992”, Stockholm Environment Institute, 1996, disponível em: http://www.sei.se/pubs/ dpubs.html

JHA, Raghbendra \& K.V. Bhanu MURTHY (2003a) “An inverse global environmental Kuznets curve". Journal of Comparative Economics, 31 (2003): 352-368.

JHA, Raghbendra \& K.V. Bhanu MURTHY (2003b) "A critique of the Environmental Sustainability Index”, Australian National University Division of Economics, Working Paper, 2003, http://ssrn. com/abstract $=380160$.

LANGE, Gleen-Marie (2007) "Environmental accounting: Introducing the SEEA-2003, System of Integrated Environmental and Economic Accounting”, Editorial, Ecological Economics 61(4): 589-591.

LOH, J., R.E. GREEN, T. RICKETTS, J. LAMOREUX, M. JENKINS, V. KAPOS, \& J. RANDERS, (2005) "The Living Planet Index: using species population time series to tack trends in biodiversity”. Phil. Trans. R. Soc. B. 360: 289-295.

MARTINEZ-ALIER, Joan. (2005) "Metabolic profiles of countries and ecological distribution conflicts". Texto de conferências na "United Nations University", Tokyo, 25 novembro 2004, e no "Institute of Economic Growth, University of Delhi”, 7 dezembro 2004. Revisado em junho de 2005 para conferência na Escola Nacional de Saúde Pública/Fundação Oswaldo Cruz, Rio de Janeiro.

MARTINS, Ana Raquel Paiva, Fernando Toledo FERRAZ \& Marcio Macedo da COSTA (2006) "Sustentabilidade ambiental como nova dimensão do Índice de Desenvolvimento Humano dos Países". Revista do BNDES, Rio de Janeiro, v. 13, n. 26: 139-162.

MUELLER, Charles C. (2004) Os economistas e as Inter-relações entre o sistema econômico e o meio ambiente. (versão preliminar), Departamento de Economia da UNB, Brasília, abril de 2004.

NEVES, Estela Maria Souza Costa (2006) A Política Ambiental e os Municípios Brasileiros. Tese de Doutorado, UFRRJ - CPDA, (mimeo) $321 \mathrm{p}$.

OECD (2001) Organização de Cooperação e de Desenvolvimento Econômico - "Aggregated Environmental Índices - Review of aggregation methodologies in use” (ENV/EPOC/SE(2001)/FINAL), disponível em www.oecd.org/env/.

OECD (2003) Organização de Cooperação e de Desenvolvimento Econômico - "OECD Environmental Indicators; Development, Measurement and Use - Reference Paper”, disponível em www.oecd.org/env/.

PNUMA - MMA - IBAMA (2002) Programa das Nações Unidas para o Meio Ambiente, Ministério do Meio Ambiente, e Instituto Brasileiro do Meio Ambiente e dos Recursos Naturais Renováveis - Geo Brasil 2002, Perspectivas do Meio Ambiente no Brasil, Brasília: Edi. Ibama, 2002.

PNUD (Programa das Nações Unidas para o Desenvolvimento) Relatório sobre o Desenvolvimento Humano. Anuais: 1990-2006. http//:www.pnud.org.br.

PRESCOTT-ALLEN (2001) The Wellbeing of Nations, Washington, DC: Island Press, 2001.

ROMEIRO, Ademar Ribeiro (org.) (2004) Avaliação e contabilização de impactos ambientais. São Paulo: Ed.Unicamp \& Imprensa Oficial.

ROMEIRO, Ademar Ribeiro (2003) “Economia ou Economia Política da Sustentabilidade”. In: MAY, Peter H., Maria C. LUSTOSA \& Valéria da VINHA (orgs.) Economia do Meio Ambiente; Teoria e Prática. Rio de Janeiro: EcoEco \& Ed. Campus, 2003: 1-29.

RYTEN, Jacob (2000) "Should there be a Human Development Index?" Paper presented at the IAOS 2000 Conference on Statistics, Development and Human Rights. Montreux, 4-8 September 2000. mimeo, $15 \mathrm{p}$.

SACHS, Ignacy (1991) “Doublespeak about Human Development?” IFDA Dossier, n. 80, Jan/Mar 1991 (Book Reviews): 91-93.

SCANDAR NETO, Wadih João (2006) Síntese que organiza o olhar: uma proposta para construção e representação de indicadores de desenvolvimento sustentável e sua aplicação para os municípios 
fluminenses. Dissertação de Mestrado, ENCE - Escola Nacional de Ciências Estatísticas, Rio de Janeiro: junho 2006, 106 p. +2 apêndices em CD-ROM.

SEI (2006) Superintendência de Estudos Econômicos e Sociais da Bahia. Indicadores de sustentabilidade ambiental. SEI \& UFBa. (Série estudos e pesquisas, 75). Salvador: SEI, 2006.

VEIGA, José Eli da (2005) Desenvolvimento Sustentável - O desafio do Século XXI. Rio de Janeiro: Ed. Garamond, 2005.

VEIGA, José Eli da (2006) Meio Ambiente \& Desenvolvimento. São Paulo: Ed. Senac.

WACKERNAGEL, Mathis, Chad MONFREDA, Dan MORAN, Paul WERMER, Steve GOLDFINGER, Diana DEUMLING \& Michael MURRAY (2005) "National Footprint and Biocapacity Accounts 2005: the underlying calculation method" (May 25, 2005), (www.footprintnetwork. org), baseado em Monfreda, C., Wackernagel, M., Deumling, D. (2004). "Establishing national natural capital accounts based on detailed ecological footprint and biological capacity accounts." Land Use Policy, 21 (2004): 231-246.

WESSELINK, Bart, Jan BAKKES, Aaron BEST, Friedrich HINTERBERGER, \& Patrick ten BRINK (2007) "Measurement beyond GDP - Background paper for de conference Beyond GDP, Measuring progress, the wealth, and the well-being of nations" (Brussels, 19 and 20 november 2007): http://www.oecd.org/dataoecd/19/33/38910732.pdf.

WORLD BANK (2005) Where is the Wealth of Nations? Measuring Capital for the XXI Century, Conference Edition, Draft of July 15, 2005.

WWF (2006) World Wildlife Fund - Living Planet Report 2006. WWF International, ZSL - Zoologic Society of LondonGlobal, Global Footprint Network Publicado pelo WWF - World Wild Fund fort the Nature (antes World Wildlife Fund), Gland, Suiça, outubro de 2006. Living Planet Report 2004. WWF International, Global Footprint Network, e UNEP-WCMC (The Unep World Conservation Monitoring Center). Publicado pelo WWF - World Wild Fund fort the Nature (antes World Wildlife Fund), Gland, Suíça, outubro de 2004. 